\title{
STRAIN AND HEALTH IMPLICATIONS OF NURSES' SHIFT WORK
}

\author{
ALESSANDRA BUJA ${ }^{1}$, ALESSANDRA ZAMPIERON ${ }^{2}$, GIUSEPPE MASTRANGELO ${ }^{1}$, \\ MARCO PETEAN ${ }^{3}$, ANGELA VINELLI ${ }^{4}$, DIANA CERNE ${ }^{5}$, and VINCENZO BALDO ${ }^{1}$ \\ ${ }^{1}$ Padua University, Padua, Italy \\ Department of Molecular Medicine, Laboratory of Public Health and Population Studies \\ ${ }^{2}$ Padua University Hospital, Padua, Italy \\ School of Pediatrics Nursing \\ ${ }^{3}$ Local Health Unit No. 4, Medio Friuli, Udine, Italy \\ Home Care Service \\ ${ }^{4}$ Padua University, Padua, Italy \\ School of Specialization in Hygiene and Preventive Medicine \\ ${ }^{5}$ Local Health Unit No. 2, Isontina, Gorizia, Italy
}

\begin{abstract}
Objectives: The study investigated whether nurses' different working schedules are associated with different levels of job-related strain, health symptoms and behavior. No reports have been accessible in the relevant literature on the possible association between shift work and job-related strain in nurses. Materials and Methods: This was a cross-sectional study conducted at a large university hospital in North-East Italy, involving 806 nurses working in selected departments. A multilevel logistic regression was applied to assess the association between work shift conditions and selected outcomes. Results: Night shifts were associated not only with higher odds of having a high Job Demand, but also with lower odds of having a high Decision Authority and consequently with a stronger likelihood of having higher levels of Job Strain (high Job Demand score $\geq 38$ and Low Decision Authority). The night shift was associated with various symptoms, particularly exhaustion $(\mathrm{p}=0.039)$ and gastric pain $(p=0.020)$. Nurses' working schedules did not affect their job satisfaction scores. Conclusions: It has been confirmed that night shifts are a risk factor for nurses' health perception and working night shifts carries a considerable degree of strain. This is a condition that hospital nursing managements need to consider carefully to avoid burnout in nursing personnel and prevent an excessive turnover in this profession, which is a recurring problem for health care organizations.
\end{abstract}

Key words:

Job strain, Stress, Job content questionnaire, Nursing

\section{INTRODUCTION}

The '24-hour society' that we have been approaching in recent years demands a social organization in which time constraints no longer limit human activities [1-3]. A recent report on working conditions has shown that about $20 \%$ of the European working population are involved in some form of shift work [4].

Shift work, and night shifts in particular, can have a negative impact on workers' health and well-being, causing: a disruption of the normal circadian rhythms of

Received: September 5, 2012. Accepted: April 25, 2013.

Corresponding author: A. Buja, Department of Molecular Medicine of the University of Padova, Laboratory of Public Health and Population Studies, Via Loredan, 18, 35128 Padova, Italy (e-mail: alessandra.buja@unipd.it). 
physiological functions; a negative effect on performance and efficiency over the 24-hour time span; a deterioration in health, in the form of disturbed sleeping and eating schedules, and more severe disorders affecting mainly gastrointestinal, neuropsychological and cardiovascular functions [5]. A recent review also showed an association between night work and a higher risk of breast cancer, and between shift work and a higher risk of cardiovascular diseases (including metabolic syndrome) [6]. Studies involving healthcare worker subjects have also demonstrated that shift work correlates with numerous health-related problems, such as fatigue, sleeping problems, anxiety, and gastrointestinal symptoms [7]. A prospective study on US female nurses doing shift work found that 6 or more years of working shifts could raise the risk of coronary heart disease in women [8]. The debate is still open, though, because some studies have generated results in conflict with those outlined above. For instance, a study in Iceland found nurses satisfied with their jobs and their assignment to shift work did not seem to disrupt their circadian cycle or induce any differences in their experience of illness [9]. The National Institute for Occupational Safety and Health in the United States nonetheless ranked nursing among the top 40 occupations with the highest prevalence of stress-related disorders [10]. Work-related stress can be defined as a pattern of emotional, cognitive, behavioral and physiological reactions to adverse and noxious aspects of work content, work organization and work environment [11]. One method used to assess the key features of the stress process is the Karasek Demand/ Control model [12], which focuses on the interaction between the objective demands of a job and the decision latitude of employees in meeting these demands. A study on nurses' health found that high levels of strain at work (high job demands and low job control), when compared with active work (high job demands and high job control), predicted a worse quality of life [13]. Although there are analyses in the literature on how working irregular hours affects the rhythm of people's lives, with deleterious effects on their mental and social functioning [14], to the best of our knowledge, only one study has analyzed the possible association between shift work and job-related stress (job strain) in nurses.

In a study by Jamal et al., rotating-shift nurses experienced a higher degree of job stress, role ambiguity, role overload and turnover intent than nurses working fixed or partially rotating shifts. In addition, rotating-shift nurses showed a lower degree of job satisfaction, work hours satisfaction and organizational commitment than fixed-shift or partially rotating-shift nurses [15].

Hence the present cross-sectional study is intended to investigate how shift work may be associated with nurses' perception of their physical health, job satisfaction, and job-related strain.

\section{METHODS}

\section{Setting and population}

This survey was conducted at a large university hospital in North-East Italy. The study population consisted of 806 nurses working shifts in selected departments: Anesthesia and Intensive Care, Internal Medicine, Specialist Medicine, General Surgery, Specialist Surgery, Maternity and Child Care, Cardio-Thoracic Medicine, Neurosciences, Oncological Diseases and Outpatients Care.

\section{Instrument}

The questionnaire used in this study was an adaptation of the questionnaire developed by Sveinsdottir [9,16,17], supplemented with some questions of the Job Content Questionnaire (JCQ) developed by Karasek et al. (1998) [12]. The original instrument proposed by Sveinsdottir was in Icelandic, so the English translations of the questions were prepared, mainly from articles published by the author. The questionnaire was initially tested on a focus group of 20 nurses expert in nursing management 
and subsequently modified to ensure that the questions were clear. The questionnaire consisted of eight sections:

- socio-demographics and professional details (14 questions),

- sleeping habits (5 questions),

- health perception (16 questions),

- part of the Job Content Questionnaire (23 questions),

- experience of illness (2 questions),

- use of drugs (2 questions),

- job satisfaction (1 question),

- lifestyle (6 questions).

There were open, multiple-choice, yes-no questions, and items to be graded on 4- or 5-point Likert scales. The socio-demographic and professional data collected included: gender, age, marital status, number of children, or dependent children, assistance given to family/friends, qualifications, types of shift in the working schedule, number of hours worked each week for part-timers, seniority on the shift. The type of working schedule was classified as: night shifts (people who alternately worked mornings, afternoons and nights), no night shifts (people who alternately worked mornings and afternoons), and no shifts (people who worked only in the mornings).

The lifestyle section of the questionnaire concerned smoking habits, alcohol use, obesity and physical exercise. The section on drug usage asked if the nurses were taking tranquillizers, antidepressants, sedatives, painkillers or asthma medication during the last 12 months. Questions on sleeping habits included an assessment of the hours of sleep per day, self-perceived adequacy of the amount of sleep, sleeping difficulties, use of sedatives, and a feeling of inadequate rest. The health perception section included questions on musculoskeletal symptoms, stress and exhaustion symptoms, migraine, diabetes, allergies, hypertension and cholesterol levels. The nurses were asked if they had consulted a physician in the last year and how many days of sick leave they had taken. Twenty-three of the 49 items in the Job Content Questionnaire Scales were included in our questionnaire and concerned skills, decision authority, psychological demand, and physical demand scales. Cronbach's $\alpha$ Reliability Coefficients of each Job Content Questionnaire Scales were assessed first in the original English version of the questionnaire [12]. A factor analysis was also performed to test whether the theoretical constructs of the Italian version corresponded to the English questionnaire, and Cronbach's $\alpha$ was measured to ensure that each item was consistent with the other items in the same subscales [18]. Finally, job satisfaction was scored on a 10-point visual analog scale, where 1 meant completely dissatisfied and 10 completely satisfied.

\section{Procedure}

The study was conducted between June and July 2011. The questionnaires were distributed to all participants by one of the researchers, accompanied by a cover letter explaining the purpose of the study. The questionnaires were completed independently and anonymously, and deposited in sealed boxes provided at each department. The completed questionnaires were collected after three weeks.

\section{Ethical issues}

The study was approved by the Padua University Hospital Management. Participation was voluntary and informed consent was obtained. Confidentiality and anonymity were guaranteed and data were analyzed only in an aggregate form.

\section{Statistical methods}

Descriptive methods were used for data analysis to obtain indices of central tendency, variability and dependence. The bivariate associations between the independent variable "shift work" and the other dependent variables were assessed using the chi square test when the variable was categorical, and the t-test when it was continuous. The socio-demographic factors emerging from the bivariate analyses, as being associated with the shift work variable, 
were retained in the multilevel regression model as covariates for adjustment. Among the symptoms, only those emerging from the bivariate analyses that could be associated $(p<0.10)$ with the shift work variable were used in the multilevel regression model as dependent variables.

Furthermore, a multilevel logistic regression analysis was applied with the third quartile of the sample distribution for each continuous outcome variable e.g. as the dependent variables - for the JCQ the third tertile corresponds to:

- a decision latitude score $\geq 72$;

- a job demand score $\geq 38$;

- a job satisfaction score $\geq 7$;

In the case of categorical variables, such as reported health symptoms, the dependent variables were dichotomized considering all answers except "never" as the index case. The independent variables had a hierarchical structure, i.e. at the patient level (first-level unit): shift work, classified as no shifts, no night shifts (mornings and afternoons), or night shifts, with the covariates sex, age, marital status, having children and relatives to assist, formal education, years of work experience, and the use of antidepressants, tranquillizers and painkillers; the department where the nurse worked was considered as the second-level unit.

The level of statistical significance was set at $p<0.05$. The statistical analyses were performed using Office 2003 Excel and STATA ver. 12.

\section{RESULTS}

The response rate for the present study was $56.5 \%$ $(\mathrm{N}=455)$. Fifteen questionnaires were excluded because they were incomplete.

The sample of nurses was mainly female (87\%), with a mean age of $38.04 \pm 8.2$ years. Table 1 shows their sociodemographic features and risk factors, grouping the nurses by their type of shift work. Night shift nurses were younger (35.09 \pm 8.1 years) with fewer years of work experience

Table 1. Socio-demographic characteristics of the study subjects

\begin{tabular}{|c|c|c|c|c|}
\hline Parameters & $\begin{array}{l}\text { No shifts } \\
(\mathrm{N}=46)\end{array}$ & $\begin{array}{l}\text { No night shifts } \\
(\mathrm{N}=94)\end{array}$ & $\begin{array}{l}\text { Night shifts } \\
(\mathrm{N}=300)\end{array}$ & $\mathrm{p}$ \\
\hline Age (years), $\mathrm{M} \pm \mathrm{SD}$ & $42.0 \pm 6.4$ & $42.8 \pm 6.7$ & $35.9 \pm 8.1$ & 0.000 \\
\hline \multicolumn{5}{|l|}{$\operatorname{Sex}[\mathrm{n}(\%)]$} \\
\hline male & $3(6.5)$ & $8(8.5)$ & $46(15.3)$ & 0.089 \\
\hline female & $43(93.5)$ & $86(91.5)$ & $254(68.2)$ & \\
\hline \multicolumn{5}{|l|}{ Marital status $[\mathrm{n}(\%)]$} \\
\hline single/unmarried & $8(17.4)$ & $15(16.0)$ & $117(39.0)$ & 0.000 \\
\hline widowed & $3(6.5)$ & $7(7.4)$ & $51(17.0)$ & \\
\hline married & $31(67.4)$ & $65(69.2)$ & $118(39.3)$ & \\
\hline separated/divorced & $4(8.7)$ & $7(7.4)$ & $14(4.7)$ & \\
\hline \multicolumn{5}{|l|}{ Children $[\mathrm{n}(\%)]$} \\
\hline no & $14(30.4)$ & $25(26.6)$ & $185(61.7)$ & 0.000 \\
\hline yes & $32(69.6)$ & $69(73.4)$ & $115(38.3)$ & \\
\hline \multicolumn{5}{|l|}{ Relatives needing care $[\mathrm{n}(\%)]$} \\
\hline no & $12(26.1)$ & $33(35.1)$ & $130(43.3)$ & 0.049 \\
\hline yes & $34(73.9)$ & $61(64.9)$ & $170(56.7)$ & \\
\hline
\end{tabular}


Table 1. Socio-demographic characteristics of the study subjects - cont.

\begin{tabular}{lcccc}
\hline \multicolumn{1}{c}{ Parameters } & $\begin{array}{c}\text { No shifts } \\
(\mathrm{N}=46)\end{array}$ & $\begin{array}{c}\text { No night shifts } \\
(\mathrm{N}=94)\end{array}$ & $\begin{array}{c}\text { Night shifts } \\
(\mathrm{N}=300)\end{array}$ & $\mathrm{p}$ \\
\hline $\begin{array}{l}\text { Education [n(\%)] } \\
\text { registered nurse }\end{array}$ & $26(56.5)$ & $79(84.0)$ & $139(46.3)$ & 0.000 \\
bachelor in nursing sciences & $8(17.4)$ & $11(11.7)$ & $137(45.7)$ & \\
specialization & $9(19.6)$ & $3(3.2)$ & $18(6.0)$ & \\
$\quad$ master in nursing sciences & $3(6.5)$ & $1(1.1)$ & $6(2.0)$ & 0.000 \\
Length of career (years), $\mathrm{M} \pm \mathrm{SD}$ & $19.3 \pm 7.8$ & $20.6 \pm 8.03$ & $12.2 \pm 8.9$ & \\
\hline
\end{tabular}

M - mean; SD - standard deviation.

(12.2 \pm 8.9 years), more often unmarried or widowed, and without children or relatives needing care.

No differences emerged concerning the nurses' lifestyle risk factors by the type of shift work. Night shift workers were more likely to take painkillers and less likely to take antidepressants. No differences were found between the three groups in terms of the nurses' reported systolic blood pressure or total cholesterol levels, sleeping

Table 2. Main characteristics of the study subjects

\begin{tabular}{|c|c|c|c|c|c|}
\hline & \multirow{2}{*}{ Parameters } & \multicolumn{3}{|c|}{$\begin{array}{l}\text { Groups } \\
\mathrm{n}(\%)\end{array}$} & \multirow{2}{*}{$\mathrm{p}$} \\
\hline & & $\begin{array}{l}\text { no shifts } \\
(\mathrm{N}=46)\end{array}$ & $\begin{array}{l}\text { no night shifts } \\
\quad(\mathrm{N}=94)\end{array}$ & $\begin{array}{l}\text { night shifts } \\
(\mathrm{N}=300)\end{array}$ & \\
\hline \multicolumn{6}{|l|}{ Behavioral risk factors } \\
\hline Body Mass Index & & $22.8(4.3)$ & $23.5(3.5)$ & $23.3(4.0)$ & 0.577 \\
\hline alcohol & & & & & 0.215 \\
\hline no & & $17(37.0)$ & $42(44.7)$ & $104(34.7)$ & \\
\hline yes & & $29(63.0)$ & $52(54.3)$ & $196(65.3)$ & \\
\hline smoking & & & & & 0.440 \\
\hline never & & $30(65.2)$ & $60(63.8)$ & $181(60.4)$ & \\
\hline ex-smoker & & $4(8.7)$ & $13(13.8)$ & $28(9.3)$ & \\
\hline occasional smoker & & $2(4.4)$ & $4(4.3)$ & $30(10.0)$ & \\
\hline habitual smoker & & $10(21.7)$ & $17(18.1)$ & $61(20.3)$ & \\
\hline physical exercise & & & & & 0.630 \\
\hline never & & $9(19.6)$ & $21(22.3)$ & $68(22.7)$ & \\
\hline$<$ once a week & & $14(30.4)$ & $33(35.1)$ & $117(39.0)$ & \\
\hline$\geq$ once a week & & $23(50.0)$ & $40(42.5)$ & $115(38.3)$ & \\
\hline \multicolumn{6}{|l|}{ Drug use } \\
\hline tranquillizers - no & & $43(93.5)$ & $79(84.0)$ & $280(93.3)$ & 0.017 \\
\hline antidepressants - no & & $44(95.7)$ & $91(96.8)$ & $299(99.7)$ & 0.021 \\
\hline painkillers - no & & $6(13.0)$ & $10(10.6)$ & $12(4.0)$ & 0.010 \\
\hline
\end{tabular}


Table 2. Main characteristics of the study subjects - cont.

\begin{tabular}{|c|c|c|c|c|}
\hline \multirow{2}{*}{ Parameters } & \multicolumn{3}{|c|}{$\begin{array}{c}\text { Groups } \\
\mathrm{n}(\%)\end{array}$} & \multirow{2}{*}{$\mathrm{p}$} \\
\hline & $\begin{array}{l}\text { no shifts } \\
(\mathrm{N}=46)\end{array}$ & $\begin{array}{l}\text { no night shifts } \\
(\mathrm{N}=94)\end{array}$ & $\begin{array}{l}\text { night shifts } \\
(\mathrm{N}=300)\end{array}$ & \\
\hline \multicolumn{5}{|l|}{ Gastrointestinal symptoms } \\
\hline constipation - no & $28(60.9)$ & $35(37.29$ & $149(49.7)$ & 0.021 \\
\hline digestive problems - no & $21(45.6)$ & $28(29.8)$ & $102(34.0)$ & 0.175 \\
\hline gastric pain - no & $27(58.7)$ & $42(44.7)$ & $125(41.7)$ & 0.095 \\
\hline \multicolumn{5}{|l|}{ Stress symptoms } \\
\hline headache - no & $10(21.7)$ & $14(14.9)$ & $59(19.7)$ & 0.511 \\
\hline low mood - no & $12(26.1)$ & $27(28.7)$ & $110(36.7)$ & 0.182 \\
\hline anxiety and tension - no & $10(21.7)$ & $16(17.0)$ & $64(21.3)$ & 0.647 \\
\hline tiredness - no & $5(11.9)$ & $8(9.3)$ & $12(4.3)$ & 0.058 \\
\hline rapid mood swings - no & $15(32.6)$ & $27(28.7)$ & $85(28.3)$ & 0.837 \\
\hline exhaustion - no & $25(54.3)$ & $32(34.0)$ & $116(38.7)$ & 0.064 \\
\hline nausea or vomiting - no & $37(80.4)$ & $68(72.3)$ & $202(67.3)$ & 0.164 \\
\hline inflammation or irritation - no & $35(76.1)$ & $63(67.0)$ & $197(65.7)$ & 0.375 \\
\hline \multicolumn{5}{|l|}{ Musculoskeletal symptoms } \\
\hline pain or stiffness in arms or legs - no & $21(45.6)$ & $40(42.5)$ & $130(43.3)$ & 0.940 \\
\hline swelling or pain in muscles or joints - no & $21(45.6)$ & $33(35.1)$ & $106(35.3)$ & 0.383 \\
\hline $\begin{array}{l}\text { problems affecting feet and legs due to prolonged } \\
\text { standing - no }\end{array}$ & $11(23.9)$ & $17(18.1)$ & $48(16.0)$ & 0.406 \\
\hline back pain - no & $12(26.1)$ & $8(8.5)$ & $47(15.7)$ & 0.023 \\
\hline persistent numbness / tingling in parts of the body - no & $24(52.2)$ & $42(44.7)$ & $166(55.3)$ & 0.195 \\
\hline Medical visits & $14(30.4)$ & $13(13.8)$ & $76(25.3)$ & 0.035 \\
\hline Absence from work & $29(63.0)$ & $55(58.5)$ & $192(64.0)$ & 0.630 \\
\hline Job satisfaction & $19(41.3)$ & $49(52.1)$ & $138(46.0)$ & 0.426 \\
\hline \multicolumn{5}{|l|}{ Karasek scales } \\
\hline decision latitude $\geq 7$ - yes & $16(34.8)$ & $24(25.5)$ & $98(32.7)$ & 0.373 \\
\hline skill discretion $\geq 37^{*}-$ yes & $12(26.1)$ & $25(26.6)$ & $99(33.0)$ & 0.380 \\
\hline decision authority $\geq 35^{*}$ - yes & $28(60.9)$ & $38(40.4)$ & $130(43.3)$ & 0.055 \\
\hline job demand $\geq 38^{*}-$ yes & $6(13.0)$ & $27(28.7)$ & $134(44.7)$ & 0.000 \\
\hline psychological demand $\geq 25^{*}$ - yes & $6(13.0)$ & $16(17.0)$ & $84(28.0)$ & 0.017 \\
\hline physical demand $\geq 15^{*}$ - yes & $4(8.7)$ & $9(9.6)$ & $55(18.3)$ & 0.050 \\
\hline $\begin{array}{l}\operatorname{high}(\mathrm{DL}<72 \& \mathrm{JD} \geq 38) \text { vs. low strain } \\
\quad(\mathrm{DL} \geq 72 \& \mathrm{JD}<38)-\text { yes }\end{array}$ & $3(18.7)$ & $18(54.5)$ & $91(62.3)$ & 0.003 \\
\hline
\end{tabular}

DL - decision latitude; JD - job demand.

* Third quartile of the sample distribution. 
habits or quality of sleep. Working night shifts was also associated with more visits to a doctor. Finally, in the bivariate analysis of the JCQ, Job Demand (job demand score $\geq 38$ ) and Psychological Demand (psychological demand score $\geq 25$ ) were associated with night shift work ( $p=0.000$ and $p=0.017$, respectively) (Table 2).

Night shifts were associated not only with higher odds of a greater Job Demand (job demand score $\geq 38$ ), but also with lower odds of having high levels of Decision
Authority (decision authority score $\geq 35$ ) and consequently a greater likelihood of having high levels of Job Strain (a high job demand score $\geq 38$ and low decision authority score $\geq 72$ ) (Table 3). The difference in painkillers intake was confirmed after adjusting for age and other covariates (data not shown).

Table 4 - night shifts were associated with certain symptoms, particularly exhaustion $(\mathrm{p}=0.039)$ and gastric pain $(\mathrm{p}=0.020)$.

Table 3. Multilevel logistic regression analyses - dependent variables: Karasek Score 3rd tertile level

\begin{tabular}{|c|c|c|c|c|}
\hline Parameters & Groups & OR & $95 \% \mathrm{CI}$ & $\mathrm{p}$ \\
\hline \multirow[t]{3}{*}{ Decision latitude $\geq 72^{*}$} & no shifts & 1.00 & & \\
\hline & no night shifts & 0.60 & $0.26-1.37$ & 0.227 \\
\hline & night shifts & 0.54 & $0.25-1.14$ & 0.105 \\
\hline \multirow[t]{3}{*}{ Skill discretion $\geq 37^{*}$} & no shifts & 1.00 & & \\
\hline & no night shifts & 1.24 & $0.53-2.91$ & 0.627 \\
\hline & night shifts & 0.96 & $0.44-2.11$ & 0.926 \\
\hline \multirow[t]{3}{*}{ Decision authority $\geq 35^{*}$} & no shifts & 1.00 & & \\
\hline & no night shifts & 0.48 & $0.22-1.04$ & 0.062 \\
\hline & night shifts & 0.39 & $0.19-0.80$ & 0.009 \\
\hline \multirow[t]{3}{*}{ Job demand $\geq 38^{*}$} & no shifts & 1.00 & & \\
\hline & no night shifts & 3.50 & $1.17-10.51$ & 0.025 \\
\hline & night shifts & 6.50 & $2.31-18.29$ & 0.000 \\
\hline \multirow[t]{3}{*}{ Psychological demand $\geq 25^{*}$} & no shifts & 1.00 & & \\
\hline & no night shifts & 1.32 & $0.43-4.06$ & 0.633 \\
\hline & night shifts & 2.60 & $0.92-7.33$ & 0.072 \\
\hline \multirow[t]{3}{*}{ Physical demand $\geq 15^{*}$} & no shifts & 1.00 & & \\
\hline & no night shifts & 1.00 & $0.24-4.11$ & 0.998 \\
\hline & night shifts & 2.41 & $0.66-8.78$ & 0.183 \\
\hline \multirow{3}{*}{$\begin{array}{l}\text { High }(\mathrm{DL}<72 \& \mathrm{JD} \geq 38) \\
\text { vs. low strain }(\mathrm{DL} \geq 72 \& \mathrm{JD}<38)\end{array}$} & no shifts & 1.00 & & \\
\hline & no night shifts & 17.49 & $2.30-133.01$ & 0.006 \\
\hline & night shifts & 43.15 & $6.15-302.88$ & 0.000 \\
\hline \multirow[t]{3}{*}{ Number of visits to doctors $\geq 4^{*}$} & no shifts & 1.00 & & \\
\hline & no night shifts & 2.58 & $1.04-6.40$ & 0.041 \\
\hline & night shifts & 1.27 & $0.59-2.74$ & 0.534 \\
\hline
\end{tabular}


Table 3. Multilevel logistic regression analyses - dependent variables: Karasek Score 3rd tertile level - cont.

\begin{tabular}{|c|c|c|c|c|}
\hline Parameters & Groups & OR & $95 \% \mathrm{CI}$ & $\mathrm{p}$ \\
\hline \multirow[t]{3}{*}{ Days of sick leave $\geq 7^{*}$} & no shifts & 1.00 & & \\
\hline & no night shifts & 1.18 & $0.49-2.83$ & 0.717 \\
\hline & night shifts & 0.94 & $0.41-2.13$ & 0.883 \\
\hline \multirow[t]{3}{*}{ Job satisfaction score $\geq 7^{*}$} & no shifts & 1.00 & & \\
\hline & no night shifts & 0.65 & $0.27-1.55$ & 0.330 \\
\hline & night shifts & 0.59 & $0.26-1.33$ & 0.203 \\
\hline
\end{tabular}

Abbreviations as in Table 2.

* Third quartile of sample distribution as in the index case. The models were adjusted for: sex, age, marital status, having children and relatives needing care, education, years of work experience, intake of antidepressants, tranquillizers, or painkillers (first level); and the ward where the nurses worked (second level).

Table 4. Multilevel logistic regression analyses - dependent variables: occurrence of symptoms in the last 12 months

\begin{tabular}{|c|c|c|c|c|}
\hline Symptoms* & Groups & OR & $95 \% \mathrm{CI}$ & $\mathrm{p}$ \\
\hline \multicolumn{5}{|l|}{ Gastrointestinal symptoms } \\
\hline \multirow[t]{3}{*}{ constipation } & no shifts & 1.00 & & \\
\hline & no night shifts & 2.99 & $1.38-6.46$ & 0.005 \\
\hline & night shifts & 1.57 & $0.78-3.17$ & 0.202 \\
\hline \multirow[t]{3}{*}{ gastric pain } & no shifts & 1.00 & & \\
\hline & no night shifts & 2.07 & $0.98-4.38$ & 0.056 \\
\hline & night shifts & 2.27 & $1.13-4.53$ & 0.020 \\
\hline \multicolumn{5}{|l|}{ Stress symptoms } \\
\hline \multirow[t]{3}{*}{ exhaustion } & no shifts & 1.00 & & \\
\hline & no night shifts & 1.70 & $0.45-6.43$ & 0.433 \\
\hline & night shifts & 3.87 & $1.07-13.98$ & 0.039 \\
\hline \multirow[t]{3}{*}{ tiredness } & no shifts & 1.00 & & \\
\hline & no night shifts & 2.34 & $1.02-5.38$ & 0.045 \\
\hline & night shifts & 2.17 & $1.02-4.64$ & 0.045 \\
\hline \multicolumn{5}{|l|}{ Musculoskeletal symptoms } \\
\hline \multirow[t]{3}{*}{ back pain } & no shifts & 1.00 & & \\
\hline & no night shifts & 4.13 & $1.42-12.05$ & 0.009 \\
\hline & night shifts & 2.13 & $0.75-4.18$ & 0.189 \\
\hline
\end{tabular}
* Index case: all subjects reporting these symptoms in the last 12 months. The models were adjusted for: sex, age, marital status, having children and
relatives under their care, education, years of work experience (first level); and the ward where the nurses worked (second level).

\section{DISCUSSION}

This study is the first (to the best of our knowledge) to correlate shift work specifically with job-related strain. Our findings indicate also an association between shift work and self-reported stress, gastrointestinal and musculoskeletal symptoms.

The nurses who worked night shifts generally had quite a different socio-demographic profile from those who did 
not: they were younger, better educated, more often single or separated, with no dependent children or relatives, and they had less work experience. This picture is easily explained by the fact that, with more years in employment and/or family ties, nurses would be more likely to ask to be spared any involvement in night shift work.

A number of studies have looked into the association between sleeping problems and night shift work. The quality of their sleep is reportedly altered in hospital nurses working on rotating shift schedules, especially in those working morning and night shifts [19] and, when comparing hospital nurses working shifts with day nurses we, like Sveinsdottir [9], did not find any such differences in the quality and quantity of sleep between our groups working different shifts. This could be because our night shift workers had less demanding family situations and found it easier to organize their social lives around their shifts. One study reported marked inter-individual differences in the sleeping problems associated with shift work, aging being the main factor explaining this variability, i.e. people $40-50$ years of age seemed to sleep worse after a night shift than younger people [20]. In contrast, another study found that older age and more years of working as a nurse significantly reduced the risk of poor sleep quality [21]. The confounding effects of age or social factors were adequately controlled in our analyses, but such an adaptation to shift work might help to explain why we found no difference in job satisfaction among our groups (avoiding the potential social or psychological disruption caused by shift work would make working nights more tolerable) [22]. This would be consistent with the findings of a previous study [9] demonstrating that a nurse's job satisfaction is independent of their type of working shift. Instead, a study an health care workers indicated that shift work could protect against job dissatisfaction [23].

No association was found between the nurses' lifestyle risk factors (smoking, lack of exercise, drinking, or obesity) and the type of shift they worked. These results are consistent with two other previous studies correlating nurses' smoking habits with their working shifts [9,24], and contrast with the findings of a review examining this association in all categories of night shift workers (the difference versus the latter could stem from health care professionals being more aware of the health risks of smoking) [25]. As for the greater use of painkillers by our night shift workers (even after adjusting for sex, age and years of employment), this finding is consistent with the Sveinsdottir's study [9]. At night, when the ratio of health care personnel to patients in the hospital wards is lower, nurses could be more likely to have to cope manually with heavy loads, as well as be exposed to greater temperature differences in the workplace, and have fewer chances of resting (often on makeshift beds).

Analyzing the answers to the JCQ (which assesses perceived stress at work) revealed no association between the nurses' global level of decision latitude and their working shifts, but when each decision latitude domain was considered separately, night shifts were associated with a lower level of decision authority (the organizationally-mediated ability of workers to make decisions about their work). This would mean that night shift nurses (even after adjusting for age, years of employment and psychological comorbidities measured by means of the proxy covariates as antidepressants, tranquillizers) saw themselves as being less autonomous in the organization of their workload and activities, and more subject to other members of staff and their employer organization.

The results of our study showed that night shifts were associated with greater physical and psychological job-related demands than day shifts. The job demand domain measures both the physical and the psychological demands of a job, assuming that a job involves both mental and physical exertions. The more traditional concept of workload considered the physical burden only, while the physiological effects of stress on the cardiovascular system, the effectiveness of mental functioning, and general levels of fatigue have been shown by an abundance of research in the 
literature to depend on both mental and physical loads, and this is taken into account in the JCQ. The greater risk of night shift workers experiencing higher levels of job demand and lower levels of decision authority explains why night shift workers are more likely to experience more severe job-related strain.

Finally, our data indicate an association between night shifts and certain self-reported gastrointestinal, stressrelated and musculoskeletal symptoms.

As for the musculoskeletal symptoms, we found back pain associated with night shift work and, consistently with this result, our sample revealed a greater use of painkilling medication by night shift workers, even after adjusting for sex, age and years of employment. These findings are comparable with those of the Sveinsdottir's study [9]. Consistently with our data, research conducted in the USA [26] also found nurses working night shifts more prone to musculoskeletal disorders. One study on nurses had already shown that job-related strain was a risk factor for musculoskeletal symptoms, and the risk was higher when this strain was combined with a perceived marked physical exertion [27]. Another study found that gastrointestinal symptoms, such as gastric pain, correlated with higher levels of strain, which is associated with gastritis and ulceration of the gastric mucosa [28]. Finally, yet another study reported that severe strain also contributed to a greater risk of tiredness and exhaustion in night shift workers. Other researchers also found that greater psychological demands correlated strongly with more severe emotional exhaustion [29]. Further studies are needed to confirm whether strain can be considered as an intermediate step linking shift work and health symptoms.

In conclusion, working night shifts carries a considerable degree of strain. This is a condition that hospital nursing managements need to consider carefully to avoid burnout in nursing personnel and prevent an excessive turnover in this profession, which is a recurring problem for health care organizations.

\section{REFERENCES}

1. Costa G. The 24-hour society: Between myth and reality. J Hum Ergol. 2001;30(1-2):15-20.

2. Presser HB. Towards a 24-hour economy. Science. 1999;284:1777-9.

3. Moore-Ede M. The twenty-four hour society: Understanding human limits in a world that never stops. Reading, Massachusetts: Addison-Wesley Publishing Company; 1993.

4. Parent-Thirion A, Macias EF, Hurley J, Vermeylen G. Fourth European Working Conditions Survey. Luxembourg: Office for Official Publications of the European Communities; 2007.

5. Costa G. The impact of shift and night work on health. Appl Ergon. 1996;27(1):9-16.

6. Wang XS, Armstrong MEG, Cairns BJ, Key TJ, Travis RC. Shift work and chronic disease: The epidemiological evidence. Occup Med. 2011;61:78-89.

7. Poissonnet CM, Veron M. Health effects of work schedules in healthcare professions. J Clin Nurs. 2000;9(1):13-23, http://dx.doi.org/10.1046/j.1365-2702.2000.00321.x.

8. Kawachi I, Colditz GA, Stampfer MJ, Willett WC, Manson JE, Speizer FE, et al. Prospective study of shift work and risk of coronary heart disease in women. Circulation. 1995;92(11):317882, http://dx.doi.org/10.1161/01.CIR.92.11.3178.

9. Sveinsdottir H. Self-assessed quality of sleep, occupational health, working environment, illness experience and job satisfaction of female nurses working different combinations of shifts. Scand J Caring Sci. 2006;20(2):229-37, http://dx.doi. org/10.1111/j.1471-6712.2006.00402.x.

10. Heim E. Job stressors and coping in health professions. Psychother Psychosom. 1991;55(2-4):90-9, http://dx.doi. org $/ 10.1159 / 000288414$.

11. European Commission. Employment and social affairs. Guidance on work-related stress - spice of life or kiss of death? Luxembourg: Office for Official Publications of the European Communities; 2000.

12. Karasek R, Brisson C, Kawakami N, Houtman I, Bongers P, Amick B. The Job Content Questionnaire (JCQ): An 
instrument for internationally comparative assessments of psychosocial job characteristics. J Occup Health Psychol. 1998;3(4):322-55, http://dx.doi.org/10.1037/1076-8998. 3.4.322.

13. Amick BC, Kawachi I, Coakley EH, Lerner D, Levine S, Colditz GA. Relationship of job strain and iso-strain to health status in a cohort of women in the United States. Scand J Work Environ Health. 1998;24(1):54-61, http:// dx.doi.org/10.5271/sjweh.278.

14. Geliebter A, Gluck ME, Tanowitz MA, Aronoff NJ, Zammit GK. Workshift period and weight change. Nutrition. 2000;16(1):27-9, http://dx.doi.org/10.1016/S0899-9007(99) 00228-2.

15. Jamal M, Baba VV. Shift-work and department type related to job stress, work attitudes and behavioural intentions: A study of nurses. J Organ Behav. 1992;13:449-64.

16. Sveinsdottir H, Gunnarsdottir H, Frioriksdottir H. Selfassessed occupational health and working environment of female nurses, cabin crew and teachers. Scand J Caring Sci.2007;21(2):262-73, http://dx.doi.org/10.1111/j.1471-6712. 2007.00465.x.

17. Sveinsdottir H, Gunnarsdottir H. Predictors of self-assessed physical and mental health of Icelandic nurses: Results from a national survey. Int J Nurs Stud. 2008;45(10):1479-89, http://dx.doi.org/10.1016/j.jinurstu.2008.01.007.

18. Baldasseroni A, Camerino D, Cenni P, Cesana GC, Fattorini E, Ferrario M, et al. [The assessment of psychosocial factors. The Job Content Questionnaire]. Information sheets ISPESL 2001;15(3):20-32. Italian.

19. Doi Y. An epidemiologic review on occupational sleep research among Japanese workers. Ind Health. 2005;43(1): 3-10, http://dx.doi.org/10.2486/indhealth.43.3.

20. Harma M. Ageing, physical fitness and shift work tolerance. ApplErgon. 1996;27(1):25-9, http://dx.doi.org/10.1016/00036870(95)00046-1.

21. Chung MH, Chang FM, Yang CC, Kuo TB, Hsu N. Sleep quality and morningness-eveningness of shift nurses. J Clin
Nurs. 2008;18:279-84, http://dx.doi.org/10.1111/j.1365-2702. 2007.02160.x.

22. Loudoun RJ, Pisarski A. Understanding and managing the risks associated with shiftwork. In: Mayhew C, Peterson C, editors. Managing OHS Risks in the Health Care Industry. North Ryde (Australia): CCH Australia; 2005. p. 155-91.

23. Conway PM, Campanini P, Sartori S, Dotti R, Costa G. Main and interactive effects of shiftwork, age and work stress on health in an Italian sample of healthcare workers. Appl Ergon. 2008;39:630-9, http://dx.doi.org/10.1016/ j.apergo.2008.01.007.

24. Reeves SL, Newling-Ward E, Gissane C. The effect of shift work on food intake and eating habits. Nutr Food Sci. 2004;34(5):216-21, http://dx.doi. org/10.1108/00346650410560398.

25. Zhao I, Turner C. The impact of shift work on people's daily health habits and adverse health outcomes. Aust J Adv Nurs. 2008;25(3):8-21.

26. Lipscomb JA, Trinkoff AM, Geiger-Brown J, Brady B. Work schedule characteristics and reported musculoskeletal disorders of registered nurses. Scand J Work Environ Health. 2002;28(6):394-401, http://dx.doi.org/10.5271/ sjweh.691.

27. Josephson M, Lagerström M, Hagberg M, Wigaeus Hjelm E. Musculoskeletal symptoms and job strain among nursing personnel: A study over a three year period. Occup Environ Med. 1997;54(9):681-5, http://dx.doi.org/10.1136/ oem.54.9.681.

28. Anda RF, Willamson DF, Escobed LG, Remington PL, Mast EE, Madans JH. Self-perceived stress and the risk of peptic ulcer disease, a longitudinal study of US adults. Arch Intern Med. 1992;152:829-33.

29. Sundin L, Hochwälder J, Bildt C, Lisspers J. The relationship between different work-related sources of social support and burnout among registered and assistant nurses in Sweden: A questionnaire survey. Int J Nurs Stud. 2007;44(5):758-69, http://dx.doi.org/10.1016/j.jnurstu.2006.01.004.

This work is available in Open Access model and licensed under a Creative Commons Attribution-NonCommercial 3.0 Poland License - http://creativecommons.org/ licenses/by-nc/3.0/pl/deed.en. 